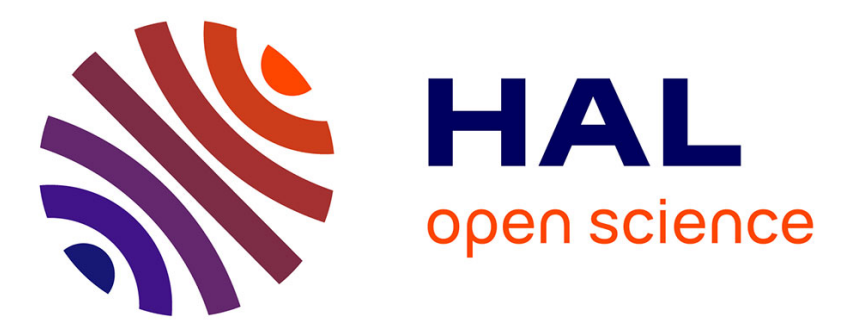

\title{
Prolonged elevated levels of c-kit+ progenitor cells after a myocardial infarction by beta 2 adrenergic receptor priming
}

\author{
Amanda Finan, Marie Demion, Pierre Sicard, Morgane Guisiano, Patrice \\ Bideaux, Kevin Monceaux, Jérôme Thireau, Sylvain Richard
}

\section{To cite this version:}

Amanda Finan, Marie Demion, Pierre Sicard, Morgane Guisiano, Patrice Bideaux, et al.. Prolonged elevated levels of c-kit+ progenitor cells after a myocardial infarction by beta 2 adrenergic receptor priming. Journal of Cellular Physiology, 2019, 10.1002/jcp.28461 . hal-02080953

\section{HAL Id: hal-02080953 https://hal.science/hal-02080953}

Submitted on 23 May 2020

HAL is a multi-disciplinary open access archive for the deposit and dissemination of scientific research documents, whether they are published or not. The documents may come from teaching and research institutions in France or abroad, or from public or private research centers.
L'archive ouverte pluridisciplinaire HAL, est destinée au dépôt et à la diffusion de documents scientifiques de niveau recherche, publiés ou non, émanant des établissements d'enseignement et de recherche français ou étrangers, des laboratoires publics ou privés. 


\title{
Prolonged elevated levels of c-kit+ progenitor cells after a myocardial infarction by beta 2 adrenergic receptor priming
}

\author{
Amanda Finan \\ Marie Demion | Pierre Sicard | Morgane Guisiano | \\ Patrice Bideaux \\ Kevin Monceaux | Jérôme Thireau | Sylvain Richard
}

Physiology \& Experimental Medicine of the Heart and Muscles (PhyMedExp), INSERM U1046, CNRS UMR 9214, University of Montpellier, Montpellier, France

\section{Correspondence}

Sylvain Richard and Amanda Finan, Physiology \& Experimental Medicine of the Heart and Muscles (PhyMedExp), INSERM (group identification U1046), CNRS. (group identification UMR 9214) and the University of Montpellier, CHU Arnaud de Villeneuve, 371 Avenue de doyen Gaston Giraud, 34295 Montpellier, France.

Email: sylvain.richard@inserm.fr;

amanda.finan-marchi@inserm.fr

\section{Funding information}

People Programme (Marie Curie Actions) of the European Union's Seventh Framework Programme FP7/2007-2013/, Grant/Award Number: 629434

\begin{abstract}
Endogenous progenitor cells may participate in cardiac repair after a myocardial infarction (MI). The beta 2 adrenergic receptor (B2-AR) pathway induces proliferation of c-kit+ cardiac progenitor cells (CPC) in vitro. We investigated if B2-AR pharmacological stimulation could ameliorate endogenous $C P C$-mediated regeneration after a MI. C-kit+ CPC B1-AR and B2-AR expression was evaluated in vivo and in vitro. A significant increase in the percentage of CPCs expressing B1-AR and B2-AR was measured 7 days post-MI. Accordingly, 24 hrs of low serum and hypoxia in vitro significantly increased CPC B2-AR expression. Cell viability and differentiation assays validated a functional role of CPC B2-AR. The effect of pharmacological activation of B2-AR was studied in C57 mice using fenoterol administered in the drinking water 1 week before $\mathrm{MI}$ or sham surgery or at the time of the surgery. MI induced a significant increase in the percentage of c-kit+ progenitor cells at 7 days, whereas pretreatment with fenoterol prolonged this response resulting in a significant elevated number of CPC up to 21 days post-MI. This increased number of CPC correlated with a decrease in infarct size. The immunofluorescence analysis of the heart tissue for proliferation, apoptosis, macrophage infiltration, cardiomyocytes surface area, and vessel density showed significant changes on the basis of surgery but no benefit due to fenoterol treatment. Cardiac function was not ameliorated by fenoterol administration when evaluated by echocardiography. Our results suggest that B2-AR stimulation may improve the cardiac repair process by supporting an endogenous progenitor cell response but is not sufficient to improve the cardiac function.
\end{abstract}

KEYWORDS

beta adrenergic receptor, c-kit cells, myocardial infarction (MI)

\section{1 | INTRODUCTION}

Improving therapeutics and interventions for ischemic heart disease remains a significant societal and clinical problem. The coronary occlusion in a myocardial infarction (MI) results in significant cardiac cell damage and death. Although, current therapies are able to attenuate symptoms and prolong life, an efficacious intervention aimed at replacing or regenerating the damaged myocardium after a $\mathrm{Ml}$ is missing. This is due to an incomplete understanding of the mechanisms governing endogenous heart regeneration after ischemia or an infarction.

Evidence has accumulated over the past 15 years to demonstrate that cardiac cell turnover occurs in healthy and diseased tissue. A number of cellular players have been proposed in this 
process, including cardiac myocytes and resident or peripheral progenitor cells (Finan et al., 2013; Finan, Kiedrowski, Turturice, Sopko, \& Penn, 2012; Fransioli et al., 2008; Jopling et al., 2010; Quaini et al., 2002). In particular, c-kit+ cardiac progenitor cells (CPC) have increasingly received attention. C-kit+ CPC proliferate in response to a $\mathrm{Ml}$ in experimental models (Fransioli et al., 2008; Urbanek et al., 2003). Their exact role, however, remains controversial. Initial reports suggested that CPC are multipotent, participating in the generation of cardiac myocytes and other mature cardiac lineages (Beltrami et al., 2003; Ellison et al., 2013). However, current literature suggests a more limited differentiation capacity of CPC, for example, acquiring an endothelial cell lineage as opposed to a myocyte lineage (Sandstedt, Jonsson, Lindahl, Jeppsson, \& Asp, 2010; van Berlo et al., 2014). Nevertheless, CPC can secrete trophic factors to the damaged myocardium (Le \& Chong, 2016). In general, increased activation of CPC has repeatedly been associated with improved cardiac function, while their depletion negatively impacts cardiac repair mechanisms (Dong et al., 2012; Ellison et al., 2013).

The mechanisms involved in the activation of CPC remain understudied. Interestingly, ischemia resulting from a MI rapidly activates the sympathetic pathway resulting in local accumulation of catecholamines in the extracellular space of the myocardium (Schömig, 1990). This resultant rise of adrenaline and noradrenaline activates the beta adrenergic receptor pathway, altering the function of myocyte and nonmyocyte cells. The combination of the increased activity of the sympathetic nervous system with an enhanced myocyte sensitivity to adrenergic stimuli has justified the clinical use of $\beta$ blocking strategies after MI. Beta blockers, either beta 1 adrenergic receptor (B1-AR) specific or nonselective, are a standard treatment after $\mathrm{MI}$ and in heart failure (Lohse, Engelhardt, \& Eschenhagen, 2003). Paradoxically, the evidence is mounting to support the use for beta 2 adrenergic receptor (B2-AR) agonists with reports citing reductions in infarct size after the treatment (Ahmet, Morrell, Lakatta, \& Talan, 2009; Ahmet et al., 2004; Zhang et al., 2010). Interestingly, $B 2-A R$ signaling has been shown to have a protective and proliferative effect in CPC in vitro (Ellison et al., 2007; Khan et al., 2013). On the basis of this evidence, we tested the hypothesis that in vivo B2-AR stimulation of endogenous CPC is beneficial after a MI. Our results indicate that priming with the $B 2-$ AR agonist, fenoterol, prolongs the c-kit+ progenitor cell response after a $\mathrm{Ml}$ and reduces infarct size. These data support a potential protective and regenerative role of B2-AR signaling in endogenous cardiac repair.

\section{2 | MATERIALS AND METHODS}

\section{1 | Animals}

All procedures were carried out in conformation with the Directive 2010/63/EU of the European Parliament and the Council of 22 September 2010 for the protection of animals used for scientific purposes (agreement number: A34-172-38), and with the approval of the local institutional animal research committee (Languedoc Roussillon, CEEA-LR-1062). Animals were housed in a temperature and hygroscopic regulated room $\left(23 \pm 1^{\circ} \mathrm{C}, 45 \pm 10 \%\right.$ humidity). The animals were synchronized to a $12 \mathrm{hr}$ day $/ 12 \mathrm{hr}$ night cycle with access to food and water ad libitum. Eight-week-old male C57BL/6 J mice (Janvier Labs, Saint Berthevin, France) were used for all experiments.

\section{2 | Myocardial infarction and fenoterol treatment}

Mice were randomly assigned a treatment: Control, Fenoterol at the time of surgery, or Fenoterol pretreatment 1 week before surgery. Fenoterol $(250 \mu \mathrm{g} / \mathrm{kg} / \mathrm{day}$, Sigma-Aldrich, Saint-Quentin-Fallavier, France) was administered in the drinking water ad libitum and maintained throughout the time course of the study (Ahmet et al., 2004). The surgeon was blinded to the treatment administered to the mice. To induce $\mathrm{MI}$, mice were anesthetized with $2 \%$ isofluorane in $100 \% \mathrm{O}_{2}$, administered an analgesic (buprenorphine $0.1 \mathrm{mg} / \mathrm{kg}$ subcutaneously), and ventilated by orotracheal intubation. A left thoracotomy was performed to expose the heart and, using a 8-0 nylon suture, the left anterior descending (LAD) coronary artery was tied by the edge of the left atrium (Lucas et al., 2015). Ischemia was verified by the sudden regional paleness of the myocardium and ST elevation. The thoracotomy site was closed whilst increasing positive end expiratory pressure. Sham animals followed the same procedure except for the omission of the LAD ligation. Animals were killed at 7 or 21 days after MI or sham surgery ( $n=7-11$ per group) by cervical dislocation. Post-mortem hearts were submitted to either enzymatic digestion for flow cytometry analysis or frozen in isopentane for histological or quantitative real-time polymerase chain reaction (qPCR) analysis.

\section{3 | Echocardiographic assessment of heart function}

Cardiac function was assessed by echocardiography 1 and 3 weeks after MI with a Vevo 2100 ultrasound system (Visualsonics, Amsterdam, Netherlands) using a 40-MHz image transducer and analysed with Vevo Lab software (version 1.7.1, RRID:SCR_015816). Echocardiography was performed under general anesthesia (3\% isofluorane during induction, followed by $2 \%$ continuous, in $100 \%$ oxygen). Body temperature was monitored with a rectal probe and maintained at $36-37^{\circ} \mathrm{C}$. All images were acquired at heart rates $>400$ beats/min for a physiologically relevant measurement. Measurements were taken from the LV parasternal long axis (B-mode) views. From these images, the stroke volume (SV: left ventricular enddiastolic volume - left ventricular end-systolic volume), cardiac output (CO: SV * heart rate), and ejection fraction (EF: $100 *$ [left ventricular end-diastolic volume - left ventricular end-systolic volume]/left ventricular end-diastolic volume) were calculated using the software with the PSLAX Trace Tool. For each echocardiographic 


\subsection{Isolation of heart cells}

Cardiac cells were isolated, as previously described, from mice killed by cervical dislocation (Demion et al., 2014). Briefly, whole hearts were retrogradely perfused (Langendorff) at $37^{\circ} \mathrm{C}$ for $6-8 \mathrm{~min}$ with a modified Tyrode's solution (in mmol/l: $\mathrm{NaCl} 113 ; \mathrm{KCL} 4.7 ; \mathrm{KH} 2 \mathrm{PO} 4$ 0.6; Na2HPO4 0.6; MgSO4 1.2; NaHCO3 12; KHCO3 10; HEPES 10; Taurine 30; $\mathrm{pH}$ 7.4) containing $0.1 \mathrm{~g} / \mathrm{ml}$ Liberase Dispase High Research Grade (Roche, Mannheim, Germany) followed by mechanical dissociation. Total isolated cells were then used in flow cytometry studies or magnetically sorted and placed in culture.

\section{5 | Flow cytometric analysis}

Cell suspensions ( $10^{7}$ cells $/ \mathrm{ml}$ in flow cytometry buffer), isolated from hearts, were incubated with a CD16/32 antibody to reduce nonspecific antibody binding. Cardiac cell suspensions were incubated with LIVE/ DEAD Fixable Green Dead Cell Stain (Thermo Fisher Scientific, Nimes, France) for $30 \mathrm{~min}$ on ice. The cells were then incubated with the following membrane surface antibodies for $20 \mathrm{~min}$ on ice: CD45 vioblue (1:50, Miltenyi Biotec, Paris, France Cat\# 130-110-664, RRID:AB_2658223), CD117 PE (1:10, Miltenyi Biotec, Paris, France Cat\# 130-102-795, RRID:AB_2660117), and $\beta 1$ adrenergic receptor (1:100, Abcam, Paris, France Cat\# ab3442, RRID:AB_10890808) or $\beta 2$ adrenergic receptor (1:100, Abbexa, Cambridge, UK). The cells were then stained with a secondary Alexa Fluor 647 antibody (1:500, Thermo Fisher Scientific, Nimes, France Cat\# A21244, RRID:AB_2535812). In vitro, CPC were cultured in control conditions (complete media, 20\% $\mathrm{O}_{2}$ ) or in stress conditions ( $1 \% \mathrm{FBS}, 5 \% \mathrm{O}_{2}$ ) for $24 \mathrm{hr}$. CPC were collected and incubated with either a $\beta 1$ adrenergic receptor or $\beta 2$ adrenergic receptor antibody followed by a secondary Alexa Fluor 647 antibody. Samples were run on a MACSQuant Analyzer 10 (Miltenyi Biotec). A multi-color flow analysis was compensated with VersaComp Antibody Capture Beads (Beckman Coulter, Villepinte, France) stained with the individual fluorescent antibodies. Results were analyzed on FlowJo software (Tree Star Inc., Ashland, OR, USA RRID:SCR_008520).

\section{6 | Cell culture}

CPC were isolated as previously described (Fransioli et al., 2008). Briefly, digested heart tissue was centrifuged to remove cardiac myocytes from smaller cells and passed through a $40 \mu \mathrm{m}$ strainer. The cells were then negatively selected for CD45 by magnetic sorting, followed by positive selection with CD117 MicroBeads (Miltenyi Biotec, Paris, France). The resulting CD117+/CD45- CPC population was cultured in DMEM/F12 media with $10 \%$ fetal bovine serum (FBS), Insulin-Selenium-Transferrin, $10 \mathrm{ng} / \mathrm{ml}$ bFGF, $10 \mathrm{ng} / \mathrm{ml}$ LIF, $20 \mathrm{ng} / \mathrm{ml}$ EGF, and penicillin/streptomycin. CPC were differentiated in $\alpha$-MEM, $10 \%$ FBS, and $10 \mathrm{nM}$ dexamethasone for 7-10 days.

\section{7 | MTT assay}

Five thousand CPC were plated per well in a 96-well dish. The cells were treated with epinephrine $1 \mathrm{nmol} / \mathrm{l}$ or fenoterol $1 \mu \mathrm{mol} / \mathrm{l}$ with or without ICl-118,551 $300 \mathrm{nmol} / \mathrm{I}$ for $48 \mathrm{hr}$ in triplicate. At the end of the time course, the cells were cultured with Thiazolyl Blue Tetrazolium Bromide (MTT, $0.5 \mathrm{mg} / \mathrm{ml}$ ) for 4 hours. DMSO was added to the dish to solubilize the formazan crystals. Absorbance was read at $570 \mathrm{~nm}$. Relative absorbance was compared with control, nontreated cells.

\section{8 | qRT-PCR}

Left ventricular tissue was homogenized in TRI Reagent (SigmaAldrich, Saint-Quentin-Fallavier, France). RNA was isolated from the tissue or cells with NucleoSpin RNA columns (Macherey Nagel, Hoerdt, France). RNA was reverse-transcribed with the Verso cDNA Synthesis Kit (Thermo Fisher Scientific, Nimes, France). Quantitative PCR of cDNA was performed in duplicate with a SYBR Green-based assay (Roche, Mannheim, Germany). The expression was normalized to endogenous Ribosomal Protein PO (RPPO) expression. The data are reported as relative quantification using the $\mathrm{ddCt}$ method. Primer sequences are available as Supporting Information.

\section{9 | Histological assessment}

Frozen hearts were sectioned at $10 \mu \mathrm{m}$ and underwent Masson's trichrome staining to measure the infarct size. Whole sections were imaged at $1 \times$ on a zoom microscope (Nikon AZ100). Infarct size was measured as the percentage of left ventricular area and epicardial and endocardial length.

Sections were incubated with fluorescein-conjugated isolectin (1:50, Vector Laboratories, Peterborough, UK, Cat\# FL-1201, RRI$\left.\mathrm{D}: A B \_2314663\right)$ to identify endothelium or rhodamine conjugated wheat germ agglutinin (1:100, Vector Laboratories, Peterborough, UK, Cat\# FL-1022, RRID:AB_2336871) to label cardiac myocytes. Proliferating and c-kit cells were examined by immunostaining for ki-67 and CD117, respectively. Sections were stained with a rabbit monoclonal ki67 (1:200, Thermo Fisher Scientific, Nimes, France Cat\# MA5-14520, RRID:AB_10979488) or a goat polyclonal CD117 antibody $(15 \mu \mathrm{g} / \mathrm{ml}$, R\&D Systems, Lille, France Cat\# AF1356, RRID:AB_354750). Mast cells were identified with a rabbit monoclonal tryptase antibody (1:500, Abcam, Paris, France Cat\# ab134931, RRID:AB_2783526). Macrophages were detected by a rat antimouse F4/80 antibody (Bio-Rad, Grabels, France, Cat\# MCA497GA, RRID:AB_323806). Alexa Fluor donkey anti-Rabbit 488 (1:500, Thermo Fisher Scientific, Nimes, France Cat\# A-21206, RRID:AB_2535792), Alexa Fluor goat anti-Rat 488 (1:500, Thermo Fisher Scientific, Nimes, France Cat\# A-11006, RRID:AB_2534074), or Alexa Fluor donkey anti-Goat 555 (1:500, Thermo Fisher Scientific, Nimes, France Cat\# A-21432, RRID:AB_2535853) were used to identify ki-67 and tryptase, macrophages, or CD117, respectively.

Apoptotic nuclei were detected in heart sections by in situ terminal deoxynucleotidyl transferase (TdT)-mediated digoxigeninconjugated deoxyuridine triphosphate (dUTP) nick end-labeling (TUNEL) with the Click-iT TUNEL Alexa Fluor 594 imaging assay (Thermo Fisher Scientific, Nimes, France, C10246). After paraformaldehyde post-fixation, slides were incubated with Proteinase $\mathrm{K}$ for 
$15 \mathrm{~min}$ followed by an additional paraformaldehyde fixation of $5 \mathrm{~min}$. Slides were then incubated with the $T d T$ reaction buffer for $10 \mathrm{~min}$. A buffer containing EdUTP and the TdT enzyme were combined on the slides for $60 \mathrm{~min}$ at $37^{\circ} \mathrm{C}$ to induce the TdT reaction. Slides were then washed with deionized water and permeabilized with PBS, 3\% BSA, and $0.1 \%$ Triton $\mathrm{X}-100$ for $5 \mathrm{~min}$. After a PBS wash, the Click-iT Plus TUNEL reaction cocktail containing the Alexa Fluor 594 dye was added to the slides for $30 \mathrm{~min}$ at $37^{\circ} \mathrm{C}$. Sections were stained with $4^{\prime}, 6$-diamidino-2-phenylindole dihydrochloride (DAPI) to mark the nuclei and mounted.

Samples were blinded before imaging and analysis. Six to eleven random fields in $\mathrm{MI}$ or sham hearts were imaged at 20x for each section on an upright fluorescent microscope (Zeiss Imager M1). Myocyte cross-sectional surface area was quantified on at least 50 transversal myocytes per section. Vessel, proliferation, macrophages, mast cells, TUNEL, and CD117 positive cell density per section were quantified. All image analysis was performed with ImageJ software (RRID:SCR_003070).

\subsection{0 | Statistics}

Values are represented as mean \pm SEM. Paired data were evaluated using Student's $t$ test. Group differences between the surgery and treatments were evaluated using the two-way analysis of variance followed by Tukey's post-hoc analysis. All statistical analysis was done using GraphPad Prism (Version 6.01, RRID:SCR_002798). $p$ value $<0.05$ was considered statistically significant.

\section{3 | RESULTS}

\section{1 | Increased B2-ARs expression on CPC after stress conditions in vivo and in vitro}

B1-AR and B2-AR levels on c-kit+/CD45- CPC was evaluated in cardiac tissue 7 days post-MI or sham surgery by flow cytometry. $M I$ resulted in a significant increase of CPC expressing B1-AR and B2-AR (3.3- and 4.1fold change compared with sham, Figure $1 \mathrm{a}, 1 \mathrm{~b})$. To mimic a $\mathrm{MI}$ in vitro, $\mathrm{CPC}$ were cultured in reduced serum (1\% FBS) and low $\mathrm{O}_{2}$ (5\%). After $24 \mathrm{hrs}$, the percentage of CPC expressing either B1-AR or B2-AR was unchanged compared with control conditions (complete media and normoxia, example flow cytometry histograms in Figure S1). However, in vitro cellular stress significantly increased the mean fluorescence intensity of B2-AR on CPC (3.4-fold difference, Figure 1d) suggesting an elevated expression level. B1-AR mean fluorescence intensity varied greatly after in vitro stress depending on the CPC preparation and was determined as insignificant (Figure 1c). Quantitative PCR validated the flow cytometry results indicating increased Adrb2, but not Adrb1, (B2$A R$ and B1-AR mRNA, respectively) after in vitro stress (Figure 1e, 1f).

\section{2 | Functional role of B2-ARs on CPC}

CPC were treated with epinephrine, a nonselective adrenergic agonist $(1 \mathrm{nmol} / \mathrm{l})$, or fenoterol, a $B 2-A R$ agonist $(1 \mu \mathrm{mol} / \mathrm{l})$, for
$48 \mathrm{hr}$. Treatment with either agonist increased CPC MTT cell viability, suggesting increased cell proliferation (Figure 2a). Co-treatment with the $\mathrm{B} 2-\mathrm{AR}$ antagonist $\mathrm{ICl}-118$, 551 reversed the proliferative effect to control.

The effect of $32-A R$ stimulation during in vitro CPC differentiation was determined using dexamethasone in the presence or not of fenoterol. Quantitative PCR demonstrated an increase of cardiac troponin $\mathrm{T}, \alpha$ smooth muscle actin, and von Willebrand factor messenger RNA (mRNA) after dexamethasone-induced differentiation, suggesting the acquisition of mature cardiac genes (Figure $2 b$ ). Interestingly, differentiation in the presence of fenoterol maintained cardiac troponin $\mathrm{T}$ and $\alpha$ smooth muscle actin mRNA expression to levels similar to undifferentiated cells. Fenoterol treatment did not reduce the capacity of $\mathrm{CPC}$ to express the endothelial cell gene von willebrand factor after dexamethasone treatment.

\section{3 | Pretreatment with fenoterol prolongs the elevation of c-kit+ cells after myocardial infarction}

The effect of B2-AR stimulation on CPC was evaluated in vivo during experimental MI. Fenoterol was administered in the drinking water after sham or MI surgery and until sacrifice. An additional group of mice was pretreated with fenoterol starting 1 week before surgery, with the treatment maintained throughout the experiment. Myocardial infarction (MI) resulted in a significant increase in c-kit+ cells as determined by immunohistochemistry (Figure 3). The effect of $\mathrm{Ml}$ on c-kit levels was exhausted 21 days post-MI (Figure 3b). Remarkably, pretreatment with fenoterol, but not administration of fenoterol at the time of $\mathrm{MI}$, significantly increased the percentage of c-kit+ cells 7 days post-surgery and this effect was sustained and remained significant at 21 days post-surgery. Quantitative PCR analysis confirmed the immunofluorescence results with increased c-kit mRNA levels at 7 and 21 days post-MI in cardiac tissue of mice pretreated with fenoterol compared with nontreated mice (Figure 3d).

To ensure that the c-kit+ cells were not of mast cell origin, colocalization of c-kit and tryptase was examined. A morphologic difference was apparent between the two cell populations. C-kit single positive cells had a smaller, spindle-shape (Figure $3 \mathrm{~g}$ ), whereas c-kit/tryptase double positive cells were large and granular (Figure 3h). The percentage of tryptase positive c-kit cells was negligible, particularly 7 days post-MI where less than $4 \%$ of the c-kit cells were double positive (Figure $3 \mathrm{e}$ ). The percentage of tryptasepositive cells that coexpressed c-kit, however, was much more important with the majority or the entire tryptase population being double positive at 21 days post-MI (Figure 3f). These data support that there is a limited contribution of mast cells in the elevated c-kit levels detected with the pretreatment of fenoterol.

\section{4 | Fenoterol treatment reduces infarct size}

Cardiac tissues were stained with Masson's Trichrome to determine infarct size (Figure 4a). Infarct size was calculated by the percentage infarct area (Figure 4b), percentage epicardial length (Figure 4c), and 
(a)

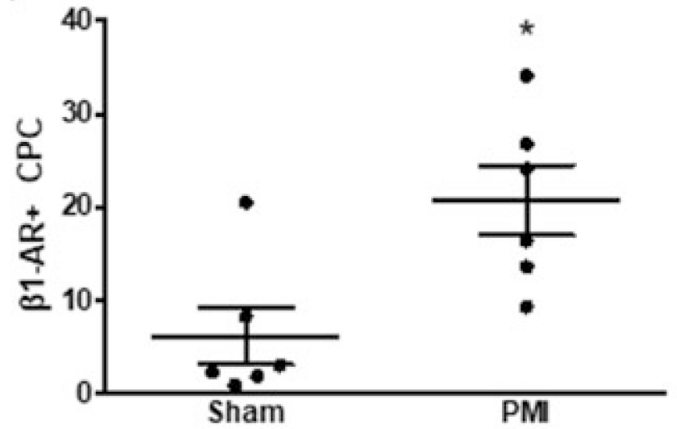

(c)

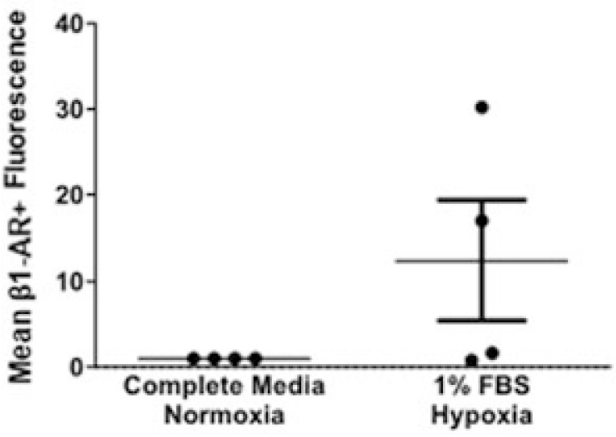

(e)

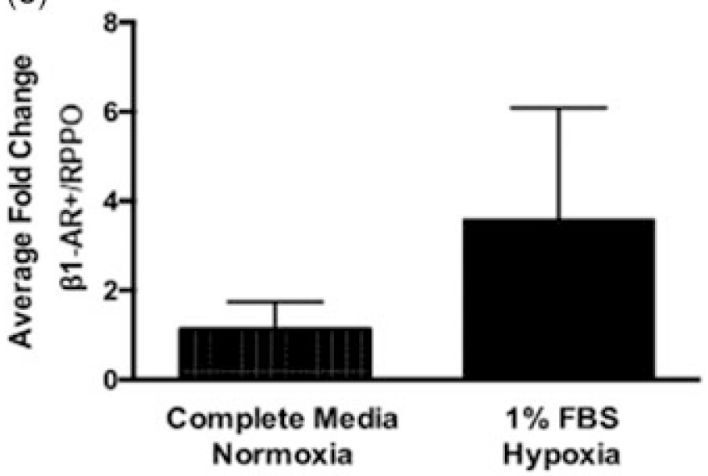

(b)

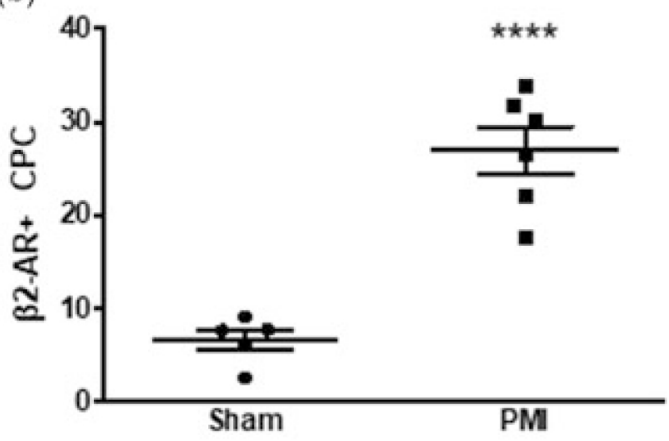

(d)

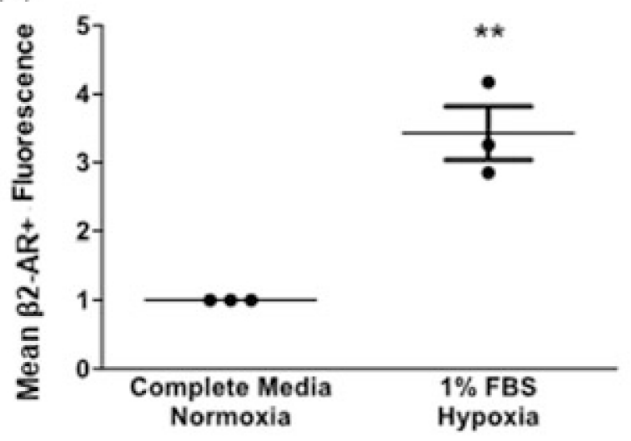

(f)

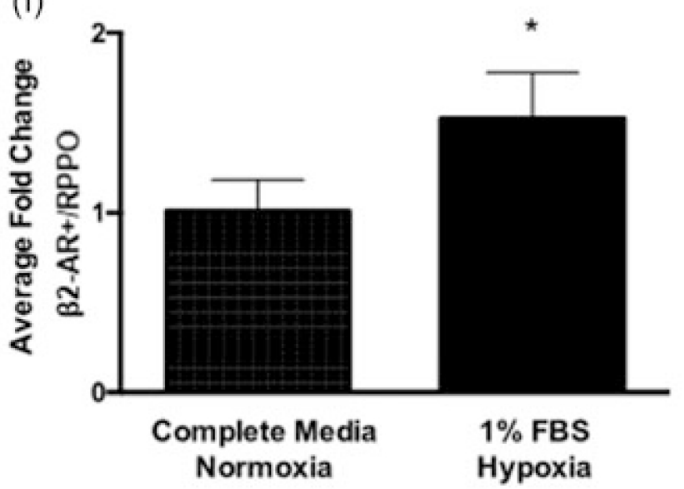

FIGURE 1 Stress conditions increase beta 1 and beta 2 adrenergic receptor (B1-AR and B2-AR) expression on CPC in vivo and in vitro. The percentage of CPC expressing B1-AR (a) and B2-AR (b) 7 days post-sham or myocardial infarction (PMI) was evaluated by flow cytometry ( $n=6$ per group, ${ }^{*} p<0.05,{ }^{* * * *} p<0.0001$ by unpaired $t$ test). CPC in vitro were cultured in control conditions of normoxia and complete media or "MI" conditions with hypoxia and low serum (1\% FBS). After $24 \mathrm{hrs}$, the cells were analyzed by flow cytometry for the median fluorescence intensity of B1-AR (c) and B2-AR (d). Quantitative PCR analysis was performed to evaluate Adrb1 (e) and Adrb2 (f) mRNA changes in the various culture conditions ( $n=3,4$ per group, ${ }^{*} p<0.05,{ }^{* *} p<0.01$ compared with complete media, $20 \% \mathrm{O}_{2}$ by unpaired $t$ test). B1-AR: beta 1 adrenergic receptor; CPC: cardiac progenitor cells; FBS: fetal bovine serum; MI: myocardial infarction; mRNA: messenger RNA

percentage endocardial length (Figure 4d). In all three measurements, pretreatment with fenoterol significantly decreased infarct size compared with nontreated animals.

\section{5 | Cardiac remodeling after $\mathrm{MI}$ and fenoterol treatment}

Cardiac hypertrophy was confirmed post-mortem as a result of MI, with no visible benefit from fenoterol treatment (Figure S2). Heart function was examined by echocardiography at 7 and 21 days postsurgery (Figure $4 \mathrm{e}, \mathrm{f}$ ). Ml significantly reduced ejection fraction, whereas pretreatment with fenoterol provoked only a trend increase of ejection fraction at 7 and 21 days post-MI ( $\approx 20 \%$ nontreated vs. $26 \%$ pretreated fenoterol).

The cell proliferative response to $\mathrm{MI}$ was evaluated by $\mathrm{ki}-67$ staining (Figure 5a). At 7 and 21 days post-MI, the number of proliferative cells in the myocardium was elevated compared with sham (Figure 5b, 5c). Fenoterol treatment did not change the number of total proliferating cells at 7 or 21 days, either in sham or MI mice. Fenoterol treatment increased the percentage of ki-67 positive c-kit cells, however, the effect was not significant (Figure 5d). 


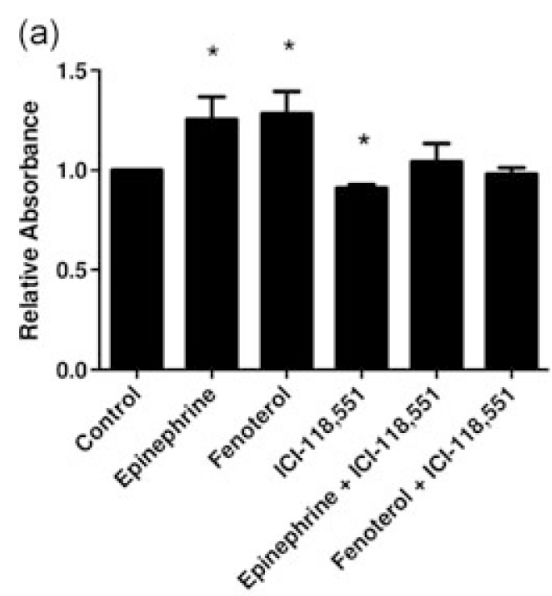

(b)

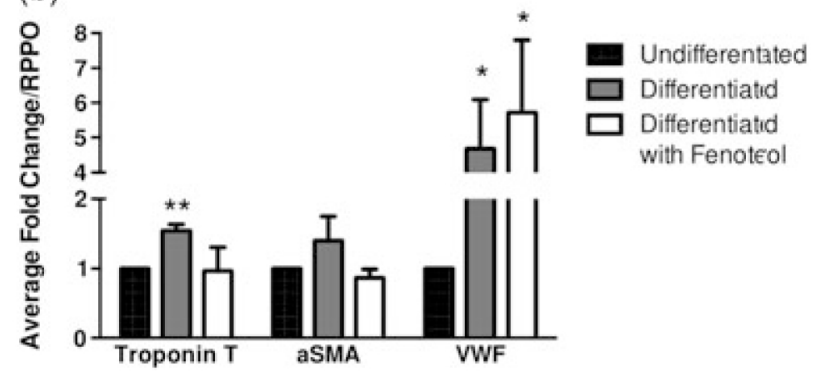

FIGURE 2 Functional role of B2-AR on CPC in vitro MTT analysis (a) was used to evaluate CPC viability after $48 \mathrm{hr}$ of treatment with the nonspecific adrenergic agonist epinephrine $(1 \mathrm{nM})$, the $B 2-A R$ agonist fenoterol $(1 \mu \mathrm{M})$, and/or the $32-A R$ antagonist ICI-118,551 $(0.3 \mu \mathrm{M})$. (b) qPCR analysis was performed on undifferentiated CPC (black bars), differentiated CPC (gray bars), and differentiated CPC treated with fenoterol (white bars) for Troponin T, $\alpha$ SMA, and VWF. ( $n=3-7,{ }^{*} p<0.05,{ }^{* *} p<0.01$ compared with control by unpaired $t$ test). ß2-AR: beta 1 adrenergic receptor; CPC: cardiac progenitor cells; mRNA: messenger RNA; MTT: thiazolyl blue tetrazolium bromide; qPCR: quantitative polymerase chain reaction

$\mathrm{Ml}$ significantly reduced vessel density in the myocardium at 7 and 21 days (Figure 6b, 6c). Pretreatment with fenoterol decreased vessel density in sham and $\mathrm{Ml}$ tissues compared with nontreated animals. The negative effect of fenoterol was transient and not significant 21 days post-MI.

MI significantly induced cardiac myocyte hypertrophy as determined by cross-sectional surface area quantification (Figure 6a). Hypertrophy was apparent at the infarct border zone 7 and 21 days post-MI (Figure 6d,e). Fenoterol treatment had no effect on cardiac myocyte hypertrophic adaptation.

As expected, MI significantly increased the presence of macrophages and TUNEL+ cells in the myocardium 7 days post-MI (Figure 7). Fenoterol treatment did not alter macrophage infiltration nor the overall number of apoptotic cells.

\section{4 | DISCUSSION}

Our data support a link between $B 2-A R$ signaling and endogenous CPC. We demonstrated that $B 2-A R$ expression on CPC is increased in response to cellular stress and plays a role in CPC viability and differentiation. In vivo, priming with the B2-AR agonist fenoterol maintains elevated levels of c-kit+ CPC longer after MI. Elevated CPC levels were associated with a decrease in infarct size. These data support a protective or reparative role of $B 2-A R$ signaling after a $\mathrm{MI}$ by enhancement of the endogenous CPC response.

Significant efforts are being directed at determining approaches to augment the natural CPC response to ischemic injury, aspiring to improve endogenous cardiac healing (Finan \& Richard, 2015). Enhancing the CPC response could be a potential therapeutic approach to diminish injury after a MI. Manipulating or exploiting signaling pathways that occur naturally after a $\mathrm{MI}$ could be a means to expand this innate, but inefficient, repair process. After a MI, the sympathetic nervous system releases excessive amounts of the catecholamines, epinephrine, and norepinephrine (Schömig, 1990). These catecholamines can act directly on resident cardiac myocytes but also on other cells types. For example, catecholaminergic signaling can regulate the egress of bone marrow stem cells from their niche (Katayama et al., 2006; Lucas et al., 2012). CPC have been demonstrated to express beta adrenergic receptors that may be implicated in their survival and proliferation state (Ellison et al., 2007; Khan et al., 2013). The implications of this pathway on CPC in vivo may provide insights on improving a natural, endogenous repair process.

B1-AR expression is common in the myocardium and cardiac myocytes (Bristow et al., 1986; Myagmar et al., 2017). In failing hearts and with increased age, B1-AR is downregulated, whereas B2-AR remains unchanged (Bristow et al., 1986; White et al., 1994). The changes in beta adrenergic receptor desensitization and cellular localization are thought to protect the heart (Najafi, Sequeira, Kuster, \& van der Velden, 2016; Rybin, Xu, Lisanti, \& Steinberg, 2000). Our results show that the expression of beta adrenergic receptors on $\mathrm{CPC}$ is dynamic by responding to stress conditions, both in vivo and in vitro. A higher percentage of CPC expressing $B 1-A R$ or $B 2-A R$ was found 1 week after MI. In vitro analysis of CPC in low serum and hypoxic conditions correlated with the in vivo study and B2-AR protein and Adrb2 mRNA levels were significantly elevated in response to cellular stress. These data suggest an adaptation of CPC to their environment and that beta adrenergic receptor signaling, particularly $B 2-A R$, may play a role in the response of $C P C$ to pathologic conditions. It remains to be determined if beta adrenergic receptors on CPC can be desensitized after long term exposure as has been described for other cell types (Benovic, Strasser, Caron, \& Lefkowitz, 1986; Shi et al., 2017).

Gender and age may also have effects on B-AR expression and signaling. Animal studies have demonstrated a higher $ß-A R$ density on male cardiac myocytes compared with female myocytes (Vizgirdi et al., 2002). This difference may be more pronounced with age, where old male hearts have a diminished response to catecholamines compared with young male and old and young female hearts (Takagi et al., 2003). There are few studies that observe a difference in catecholaminergic signaling between human males and females (Keller \& Howlett, 2016). In vitro sex-related biological responses 
(a)

7 day

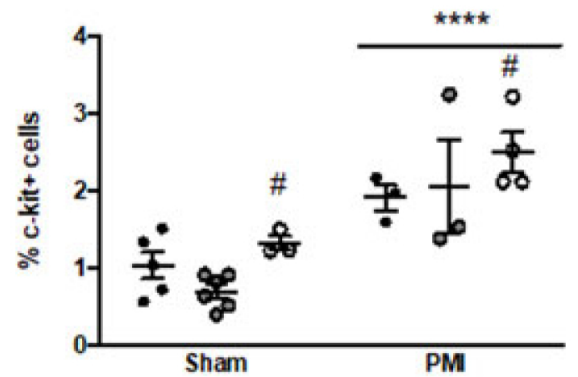

(c)

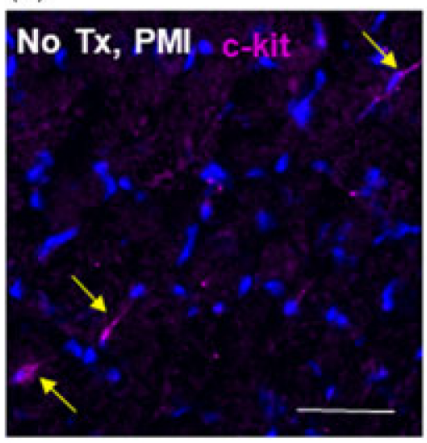

(e)

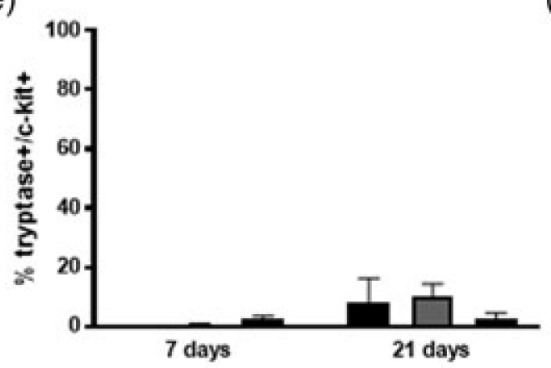

(g)

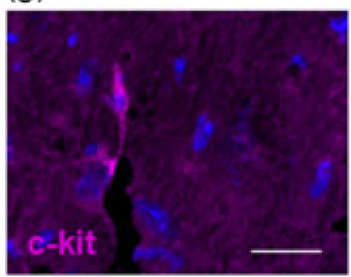

(h) (b)

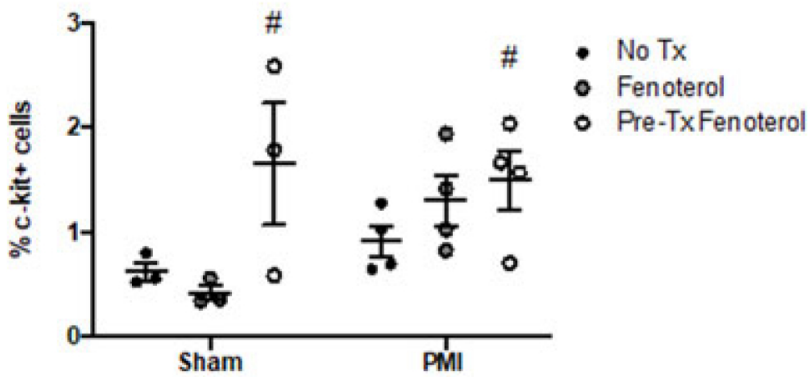

(d)
21 day
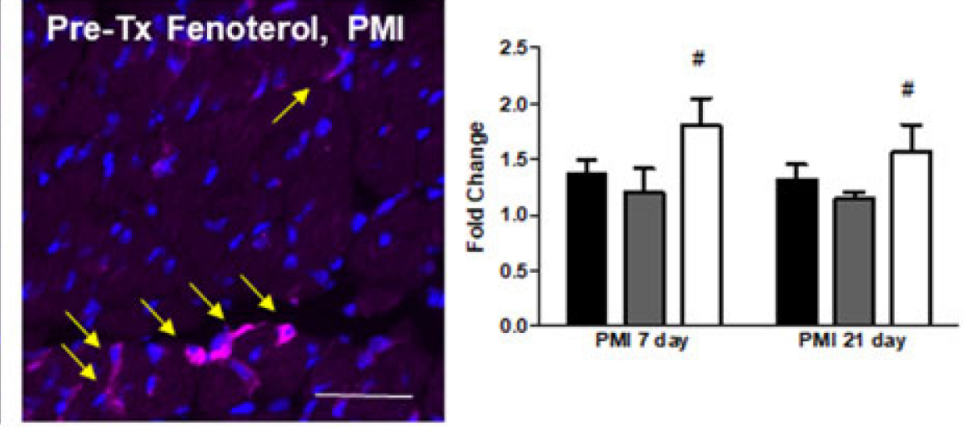

(f)

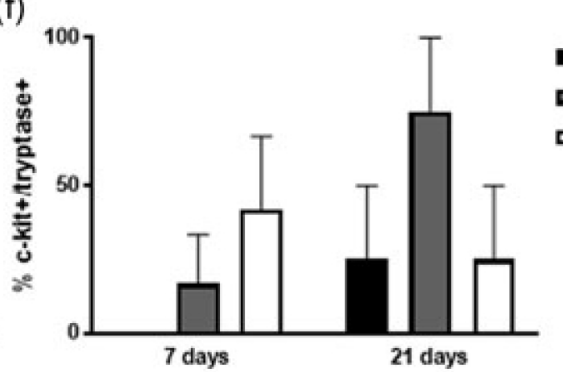

- No Tx

口 Fenoterol

口 Pre-Tx Fenoterol
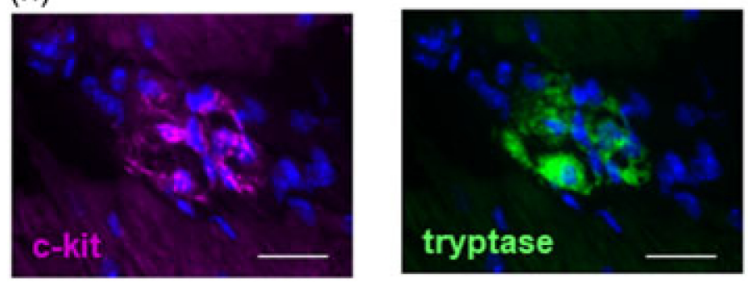

FIGURE 3 Pretreatment with fenoterol prolongs elevated levels of c-kit+ cells after myocardial infarction Quantification of the percentage of c-kit+ cells from nontreated (black circles), fenoterol-treated (gray circles), and fenoterol pretreated (white circles) mice 7 (a) and 21 (b) days post-sham or MI surgery. (c) Representative images of myocardial sections from sham and PMI 7 days post-surgery from nontreated and fenoterol pretreated mice. CPC were identified with a c-kit antibody (purple) and nuclei with DAPI (blue). Yellow arrows identify c-kit+ cells. The white scale bar represents $50 \mu \mathrm{M}$. (d) qPCR analysis for the c-kit transcript from ventricles of nontreated and fenoterol mice 7 and 21 days post-MI. (e) Percentage of c-kit+ cells that coexpressed the mast cell marker tryptase and (f) the percentage of tryptase+ cells that coexpressed c-kit at 7 and 21 days post-MI. (g) Representative images of a c-kit+/tryptase- cell and (h) a cluster of c-kit+/tryptase+ cells. CPC were identified with a c-kit antibody (purple), mast cells were identified by a tryptase antibody (green), and nuclei with DAPI (blue). The white scale bar represents $25 \mu \mathrm{M} . n=3-6$ animals per group. ${ }^{* * *} p<0.001$ compared with sham; ${ }^{*} p<0.05$ compared with nontreated mice by two-way ANOVA with Tukey's post-hoc test. ANOVA: analysis of variance CPC: cardiac progenitor cells; DAPI: 4',6-diamidino-2-phenylindole dihydrochloride; MI: myocardial infarction; PMI: post- myocardial infarction [Color figure can be viewed at wileyonlinelibrary.com] 
(a)

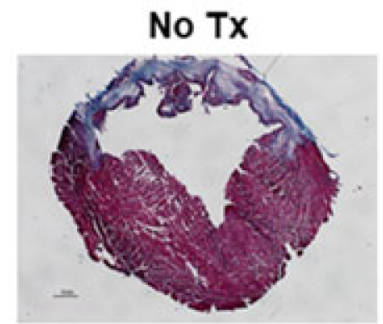

Fenoterol

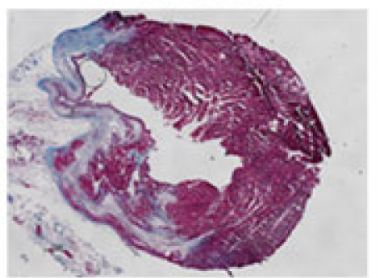

Pre-Tx Fenoterol

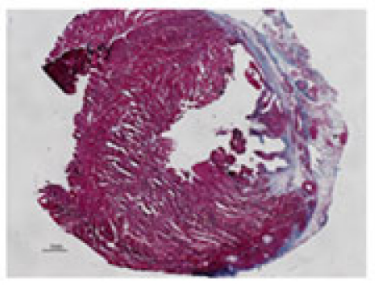

(e)

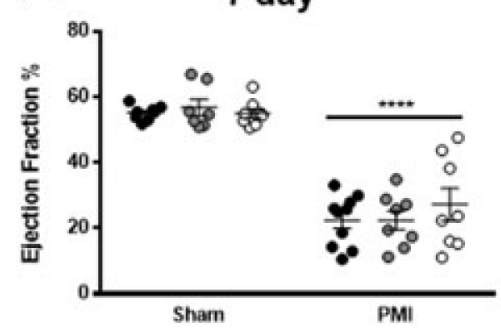

(b)
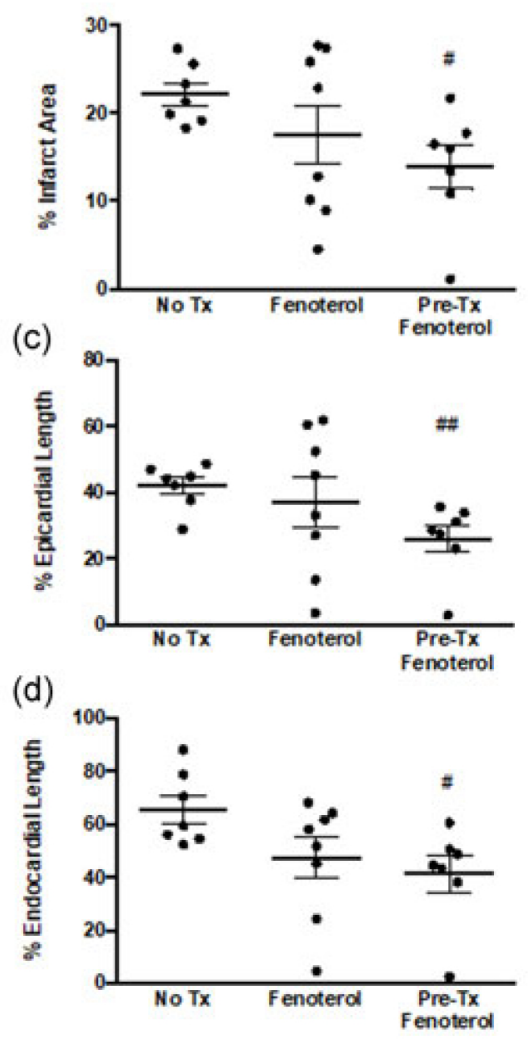

(f)

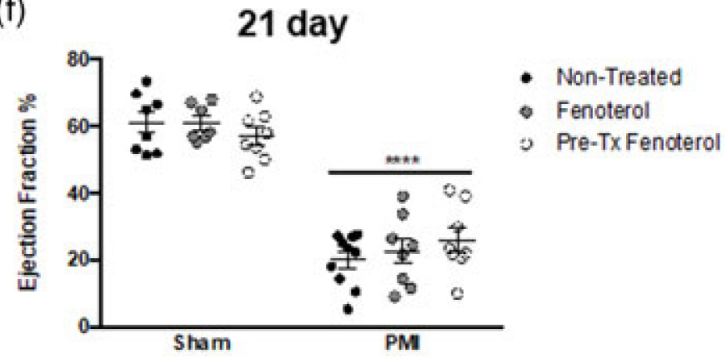

FIGURE 4 Fenoterol treatment reduces infarct size (a) Representative images of Masson's trichrome stained myocardial sections from nontreated, fenoterol-treated, and fenoterol pretreated mice 7 days PMI. Quantification of percentage infarct area (b) and epicardial (c) and endocardial (d) length 7 days PMI determined by Masson's trichrome staining. Ejection fraction determined by echocardiography (e) 7 and (f) 21 days post-surgery from sham and PMI mice ( $n=7-11$ animals per group). ${ }^{* * * *} p<0.0001$ compared with sham, ${ }^{\#} p<0.05,{ }^{\# \# p<0.01}$ compared with nontreated by two-way ANOVA with Tukey's post-hoc test. ANOVA: analysis of variance; PMI: post- myocardial infarction [Color figure can be viewed at wileyonlinelibrary.com]

of human CPC have been described for TNF- $\alpha$ signaling (Straface et al., 2017). Age-related differences in CPC have also been reported (Rota, Goichberg, Anversa, \& Leri, 2015). Our current study is limited with a focus on young male mice. Future studies are required to extend the information presented herein to the realm of gender and age differences.

Our study is in agreement with previous reports demonstrating that MI produces a transient rise in the c-kit+ CPC population (Dong et al., 2012; Fransioli et al., 2008). CPC were significantly increased in the left ventricle 7 days post-MI but had returned to normal levels by 21 days post-MI. In support of a functional role of B2-AR on CPC, treatment with fenoterol before $\mathrm{MI}$ resulted in prolonged, elevated levels of c-kit+ cells in the myocardium as demonstrated by both qPCR and immunohistochemistry. The contribution of mast cells in the increased c-kit population after fenoterol treatment was negligible. Functionality of CPC B2-AR was confirmed in vitro through viability and differentiation assays. Both epinephrine and fenoterol stimulated CPC viability by MTT suggesting an increase in proliferation. This response was reversed when B2-AR were blocked by $\mathrm{ICl}-118,551$. A pro-proliferative in vitro effect of $B 2-A R$ stimulation has been similarly reported previously (Ellison et al., 2007; Khan et al., 2013; Wallner et al., 2016). This study is limited because of the inability to determine if the c-kit+ cells in the myocardium are, in fact, resident CPC, recruited peripheral c-kit+ 
(a)
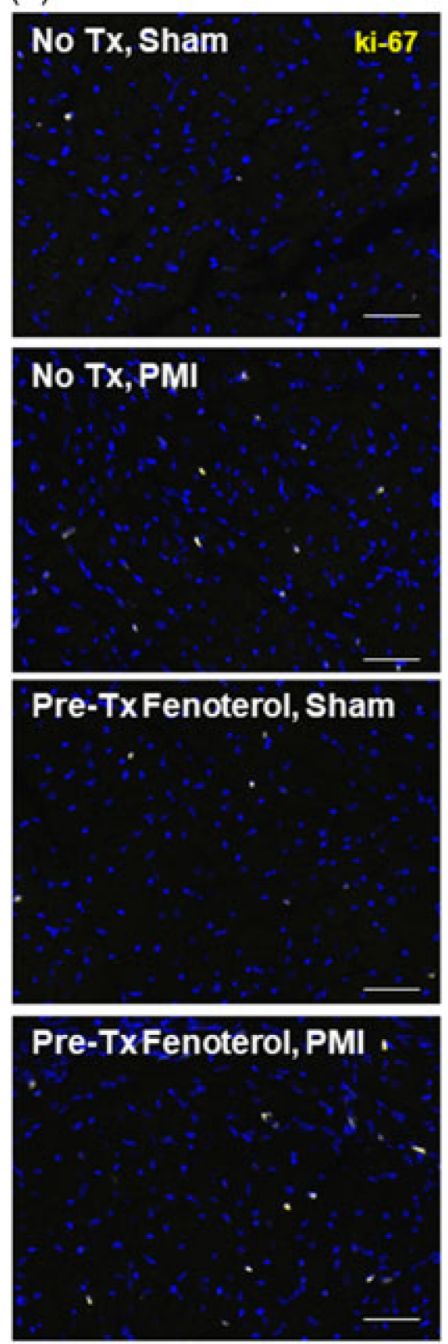

(b)

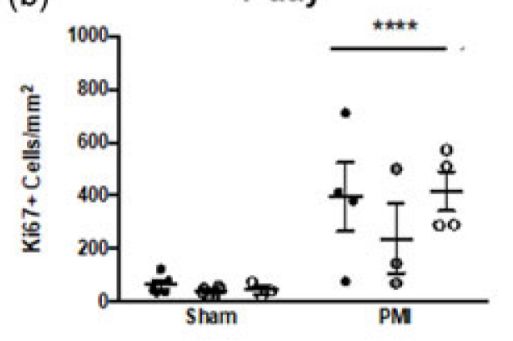

- NoTx

Fenoterol

- Pre-TxFenderal

(c)

21 day

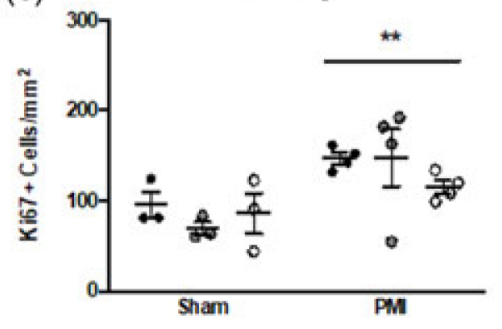

(d)

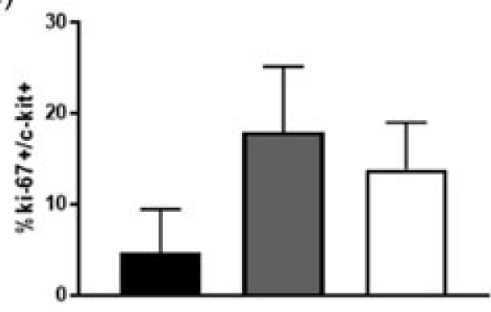

(e)

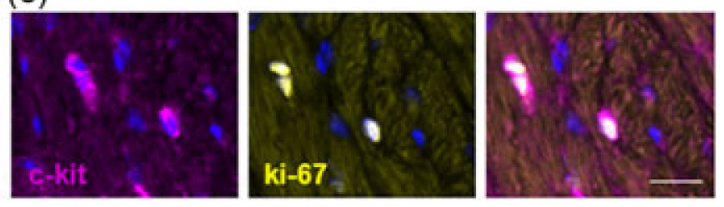

FIGURE 5 Myocardial infarction, but not fenoterol treatment, increases proliferation (a) Representative images of myocardial sections from sham and PMI 21 days post-surgery from nontreated and fenoterol pretreated mice. Proliferating cells were labeled with ki-67 (yellow) and nuclei with DAPI (blue). The white scale bar represents $50 \mu \mathrm{M}$. Quantification of total proliferating cells in the myocardium by ki-67 staining in nontreated, fenoterol-treated, and fenoterol pretreated mice 7 (b) and 21 (c) days post-sham or MI surgery. (d) Percentage of c-kit+ cells that were co-labeled with ki-67 at 7 days post-MI. (e) Representative image of c-kit+/ki-67+ cells from a mouse 7 days post-MI pretreated with fenoterol. Proliferating cells were labeled with ki-67 (yellow), CPC were detected with c-kit (purple), and nuclei with DAPI (blue). The white scale bar represents $20 \mu \mathrm{M} . n=3-6$ animals per group. ${ }^{* *} p<0.01,{ }^{* * * *} p<0.0001$ compared with sham by two-way ANOVA with Tukey's posthoc test. ANOVA: analysis of variance; DAPI: DAPI: 4',6-diamidino-2-phenylindole dihydrochloride; MI: myocardial infarction; PMI: postmyocardial infarction [Color figure can be viewed at wileyonlinelibrary.com]

progenitor cells, or a combination of both populations. Regardless of the origin of the c-kit+ cells, the accumulation of c-kit+ cells in the heart after a $\mathrm{MI}$ has repeatedly been associated with improved cardiac repair (Dong et al., 2012; Fazel, 2006). Therefore, the importance of the maintained elevated levels of c-kit+ cells in the heart 3 weeks PMI is not diminished despite the experimental limitations of the study.

One of the proposed functions of CPC is their ability to differentiate into more mature cardiac cell types (Beltrami et al., 2003; Ellison et al., 2013; Fanton et al., 2016). The ß2-AR pathway has previously been suggested to affect the stemness/commitment balance of cardiac progenitor cells (Pagano et al., 2018). Here, we demonstrated that the differentiation of CPC after dexamethasone treatment increases the expression of genes associated with mature cardiac cells, cardiac myocytes, smooth muscle cells, and endothelial cells. Interestingly, a B2-AR agonist blunted the differentiation of the cardiac myocyte and smooth muscle cell lineage without affecting endothelial cell mRNA expression. The effect of fenoterol on CPC cardiac differentiation may, in part, explain the lack of functional improvement with an increased CPC number even if in vivo CPC cardiac myocyte differentiation has been suggested to be negligible (van Berlo et al., 2014). Fenoterol pretreatment in vivo resulted in an early drop in myocardial vessel density that was recovered by 21 days. A secondary, negative effect of fenoterol on vessels may 
(a)

No Tx

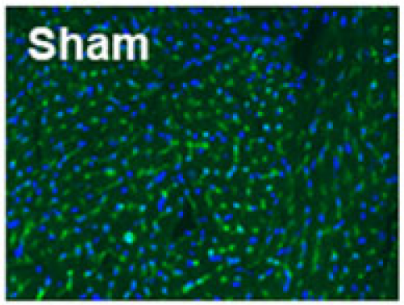

\section{Sham}
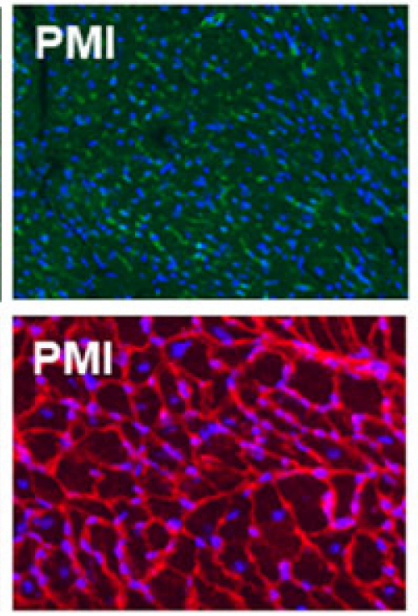

Fenoterol
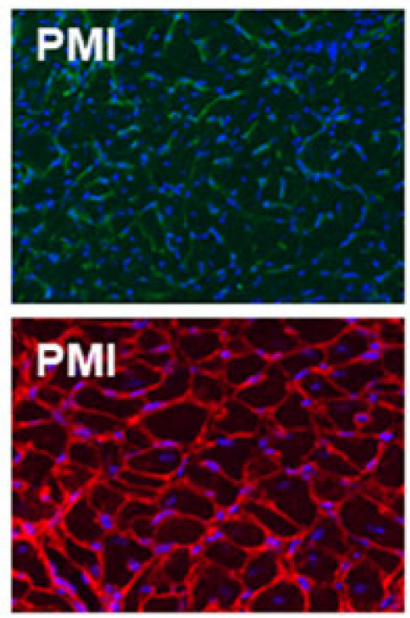

Pre-Tx Fenoterol
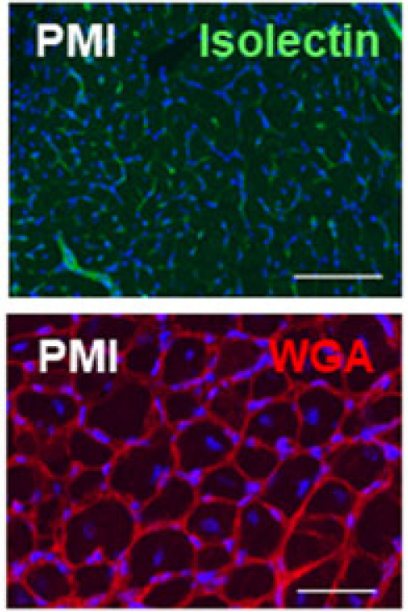

(b)

$$
7 \text { day }
$$

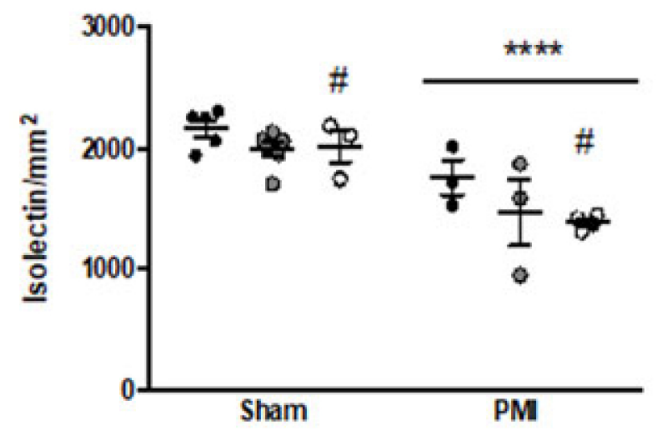

(d)

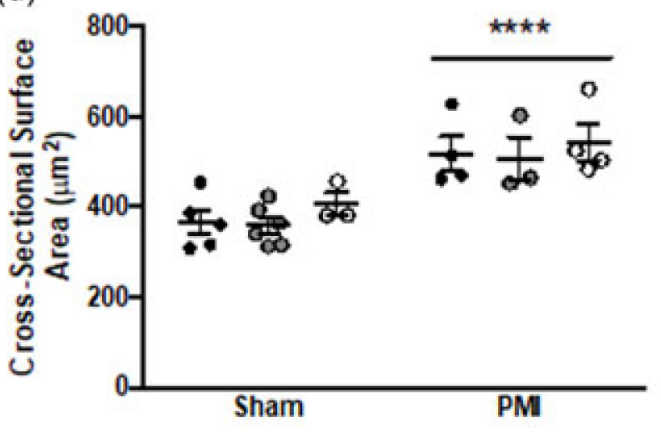

(c)

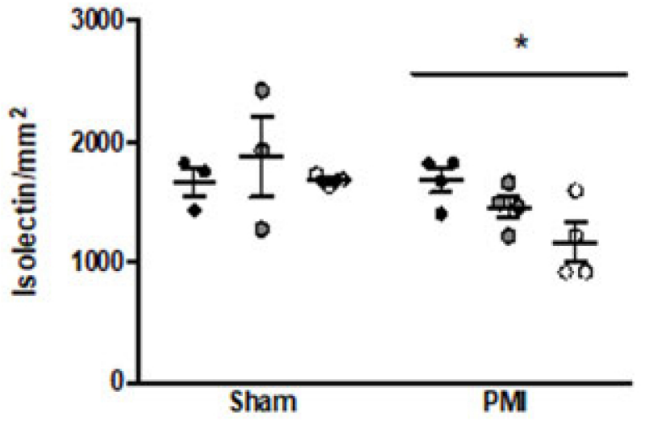

(e)

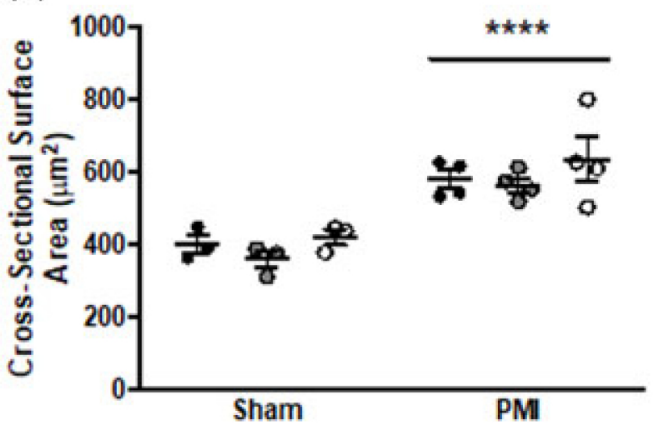

FIGURE 6 Vessel density reduction and cardiac myocyte cross-sectional surface area increase by myocardial infarction are not rescued by fenoterol treatment (a) Representative images of myocardial sections 7 days post-surgery from sham nontreated and MI nontreated, fenoterol-treated, and fenoterol pretreated mice. Vessels were labeled with isolectin (green), cardiac myocyte membrane was labeled with wheat germ agglutinin (red), and nuclei with DAPI (blue). Quantification of vessel density by isolectin staining from nontreated (black circles), fenoterol-treated (gray circles), and fenoterol pretreated (white circles) mice 7 (b) and 21 (c) days post-sham or MI surgery. Quantification of cardiac myocyte cross-sectional surface area staining from nontreated (black circles), fenoterol-treated (gray circles), and fenoterol pretreated (white circles) mice 7 (d) and 21 (e) days post-sham or MI surgery. The white scale bar represents $100 \mu \mathrm{M}$ in images labeled with isolectin and $50 \mu \mathrm{M}$ in images labeled with wheat germ agglutinin. $n=3-6$ animals per group. ${ }^{*} p<0.05$, ${ }^{* * * *} p<0.0001$ compared with sham; ${ }^{*} p<0.05$ compared with nontreated mice by two-way ANOVA with Tukey's post-hoc test. ANOVA: analysis of variance; DAPI: DAPI: 4',6-diamidino-2-phenylindole dihydrochloride; MI: myocardial infarction; PMI: post-myocardial infarction [Color figure can be viewed at wileyonlinelibrary.com] 
(a)
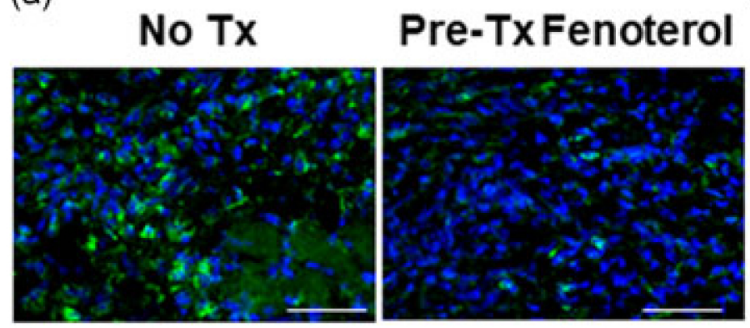

(c)

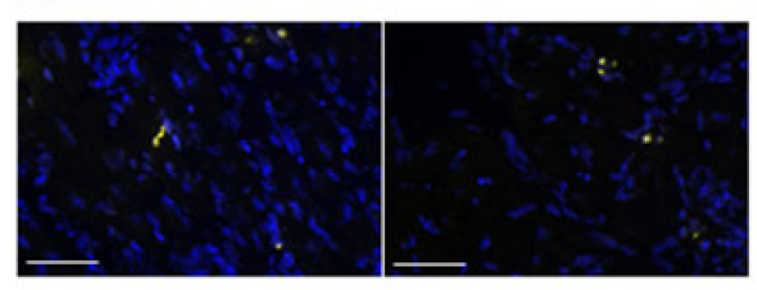

(b)
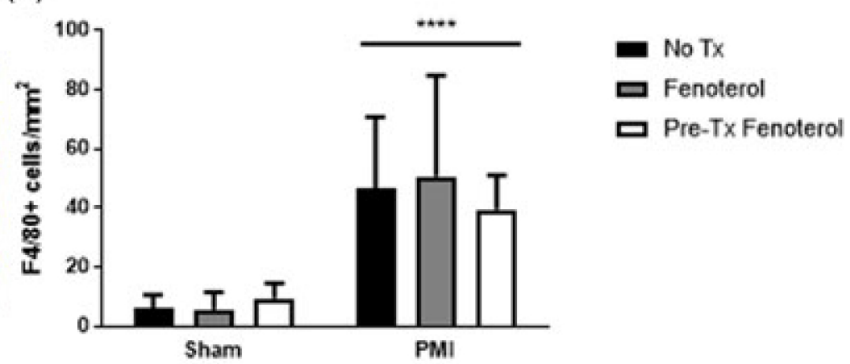

(d)

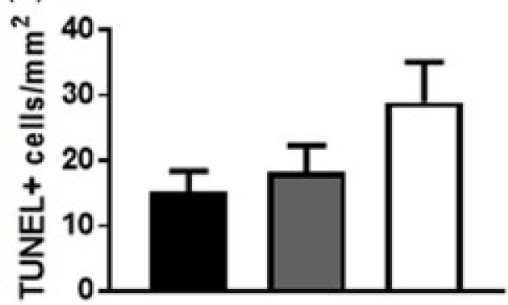

FIGURE 7 Fenoterol treatment does not alter macrophage infiltration or apoptosis after a myocardial infarction (a) Representative images of myocardial sections 7 days post-surgery from MI nontreated and fenoterol pretreated mice. Macrophages were labeled with F4/80 (green) and nuclei with DAPI (blue). Quantification of macrophage density from nontreated (black bars), fenoterol-treated (gray bars), and fenoterol pretreated (white bars) mice 7 days (b) post-sham or MI surgery. (c) Representative images of TUNEL+ cells (yellow) 7 days post-surgery from MI nontreated and fenoterol pretreated mice. Quantification of TUNEL-positive cells from nontreated (black circles), fenoterol-treated (gray circles), and fenoterol pretreated (white circles) mice 7 (d) days post-MI surgery. The white scale bar represents $50 \mu M$ in images. $n=3-6$ animals per group. ${ }^{* * *} p<0.0001$ compared with sham by two-way ANOVA with Tukey's post-hoc test. ANOVA: analysis of variance; DAPI: DAPI: 4',6-diamidino-2-phenylindole dihydrochloride; MI: myocardial infarction; TUNEL: terminal deoxynucleotidyl transferase dUTP nick endlabeling [Color figure can be viewed at wileyonlinelibrary.com]

account for this initial effect (Hirst et al., 2004). However, the increased CPC number with a maintained efficiency to differentiate into endothelial cells may have compensated for this effect at the 21 day time point. Further studies are required to clarify the effect of beta adrenergic receptor signaling on the viability and migration of CPC (Ellison et al., 2007; Galasso et al., 2013).

We found a benefit of fenoterol treatment on infarct size and resident CPC only in animals treated 1 week before surgery. It is well known that $\mathrm{MI}$ induces excessive catecholamine release (Lameris et al., 2000; Prichard, Owens, Smith, \& Walden, 1991; Schömig, 1990). The post-MI exogenous stimulation of B2-AR by fenoterol may have a negligible effect when compared with the endogenous catecholamines. Nevertheless, the benefit of fenoterol pretreatment fits the concept of preconditioning. In vitro preconditioning of progenitor cells for myocardial regeneration by growth factors, hypoxia, or even fenoterol has been demonstrated to improve cell survival in vivo and to improve cardiac repair (Hinkel, 2016; Khan et al., 2013; Mayorga, Finan, \& Penn, 2009). Preconditioning performed in a porcine model of MI was associated with increased mobilization of peripheral progenitor cells (Lukovic et al., 2016). While it is currently unknown if preconditioning in vivo stimulates endogenous CPC, it could potentially be hypothesized that stimulation of $B 2-A R$ by fenoterol could prime the CPC population thus resulting in an improved response.

Studies of beta adrenergic receptor signaling in the heart have primarily focused on its role in controlling heart rhythm and contractile force. In heart failure, the downstream Gi pathway induced by beta adrenergic receptors stimulation results in cardiac maladaptive remodeling and failure (Woo \& Xiao, 2012). In particular, B2-AR stimulation can negatively alter cardiac myocyte contractility, beat rate, and arrhythmogenicity (Lang et al., 2015; Woo \& Xiao, 2012). Conversely, B2-AR signaling can also be cardioprotective by favoring an Akt/antiapoptotic pathway (Communal, Singh, Pimentel, \& Colucci, 1998; Communal, Singh, Sawyer, \& Colucci, 1999). There is clearly a balance between B2-AR signaling being beneficial or detrimental. Importantly, in this study, we used fenoterol, which is selective for the favorable Gs pathway (Fajardo et al., 2013; Xiao et al., 2003). Fenoterol has been demonstrated to be beneficial in models of hypertension, dilated cardiomyopathy, and doxorubicin cardiotoxicity (Ahmet et al., 2009; Ahmet et al., 2004; Bernstein et al., 2005). These studies also indicated functional improvements with fenoterol. Fenoterol was associated with improved cardiac remodeling by decreased infarct size in our study but these improvements did not translate into favorable LV function. The exact reason for this is unclear. This discordant phenomenon has been evidenced in other studies, including preclinical and clinical trials (Janssens et al., 2006; Makkar et al., 2012; Moelker et al., 2006; Roncalli et al., 2011). It has been suggested that improvements in infarct size alone are not sufficient to improve cardiac function as ejection fraction is influenced by a number of confounding factors including electrical activation pattern, rhythm, and neurohormonal balance (Makkar et al., 2012). 
Overall apoptotic levels in the myocardium were similar between nontreated and fenoterol-treated animals. As B2-AR signaling favors the Akt/antiapoptotic pathway in in vitro cardiac myocytes, the reasons behind our results are unclear (Communal et al., 1998; Communal et al., 1999). Future examination of the apoptotic cells in vivo after B2-AR agonist treatment could determine if this method of stimulation favors specifically an anti-apoptotic effect solely in cardiac myocytes or if other cell populations are favorably or detrimentally affected.

While this study primarily focused on the effect of fenoterol and B2-AR stimulation to manipulate the endogenous CPC population, the effect of fenoterol on macrophage infiltration was also examined. The importance of 32 -AR signaling in leukocyte recruitment after a MI has previously been reported (Grisanti et al., 2016; Grisanti, Traynham et al., 2016). These studies demonstrated that lack of B2-AR expression in bone marrow cells and their leukocyte progenitors results in a decreased immune cell recruitment after a MI. On the basis of these studies, it would be expected that stimulation of B2-AR would increase the inflammatory response post-MI. However, in our study, we did not find any significant effects on macrophage accumulation in the myocardium with fenoterol treatment 7 days post-MI. This may again be because of the endogenous catecholamine levels that naturally occur after a MI. The levels may be so high that the addition of B2-AR antagonism by fenoterol in the tested dose does not augment the endogenous response. This likely applies to the c-kit cell response where the treatment of fenoterol, at the time of PMI, did not improve the CPC response. B2-AR pre-stimulation alone may be sufficient to prime a c-kit+ cell response but not one of a macrophage.

In summary, our results provide evidence that B2-AR signaling may stimulate an endogenous cardiac repair process by supporting a $C P C$ response. $B 2-A R$ agonism stimulates $C P C$ viability both in vitro and in vivo, prolonging elevated levels of CPC in response to MI. This, in turn, sustains an endogenous cardiac repair process, improving infarct size. While the clinical relevance of a B2-AR agonist pretreatment is limited, this study expands on antecedent studies suggesting that B2-AR agonists may provide an effective approach to augmenting endogenous cardiac repair.

\section{FUNDING}

This work was supported by the People Programme (Marie Curie Actions) of the European Union's Seventh Framework Programme FP7/ 2007-2013/ under REA grant agreement number 629434 to A. F.

\section{CONFLICT OF INTERESTS}

The authors declare that there are no conflict of interests.

\section{AUTHOR CONTRIBUTIONS}

A. F. and S. R. designed the study. A. F., M. D., P. S., M. G., P. B., and P. M. carried out the experiments. A. F, M. D., P. S., J. T., and S. R. contributed to the interpretation of the results. A. F. took the lead in writing the manuscript with input from all authors.

\section{REFERENCES}

Ahmet, I., Krawczyk, M., Heller, P., Moon, C., Lakatta, E. G., \& Talan, M. I. (2004). Beneficial effects of chronic pharmacological manipulation of $\beta$-adrenoreceptor subtype signaling in rodent dilated ischemic cardiomyopathy. Circulation, 110(9), 1083-1090. https://doi.org/10. 1161/01.CIR.0000139844.15045.F9

Ahmet, I., Morrell, C., Lakatta, E. G., \& Talan, M. I. (2009). Therapeutic efficacy of a combination of a beta1-adrenoreceptor (AR) blocker and beta2-AR agonist in a rat model of postmyocardial infarction dilated heart failure exceeds that of a beta1-AR blocker plus angiotensinconverting enzyme inhibitor. The Journal of Pharmacology and Experimental Therapeutics, 331(1), 178-185. https://doi.org/10.1124/ jpet.109.157107

Beltrami, A. P., Barlucchi, L., Torella, D., Baker, M., Limana, F., Chimenti, S., \& Anversa, P. (2003). Adult cardiac stem cells are multipotent and support myocardial regeneration. Cell, 114(6), 763-776.

Benovic, J. L., Strasser, R. H., Caron, M. G., \& Lefkowitz, R. J. (1986). Betaadrenergic receptor kinase: Identification of a novel protein kinase that phosphorylates the agonist-occupied form of the receptor. Proceedings of the National Academy of Sciences of the United States of America, 83(9), 2797-2801.

van Berlo, J. H., Kanisicak, O., Maillet, M., Vagnozzi, R. J., Karch, J., Lin, S.C. J., \& Molkentin, J. D. (2014). c-kit+ cells minimally contribute cardiomyocytes to the heart. Nature, 509(7500), 337-341. https://doi. org/10.1038/nature13309

Bernstein, D., Fajardo, G., Zhao, M., Urashima, T., Powers, J., Berry, G., \& Kobilka, B. K. (2005). Differential cardioprotective/cardiotoxic effects mediated by $\beta$-adrenergic receptor subtypes. American Journal of Physiology - Heart and Circulatory Physiology, 289(6), H2441-H2449. https://doi.org/10.1152/ajpheart.00005.2005

Bristow, M. R., Ginsburg, R., Umans, V., Fowler, M., Minobe, W., Rasmussen, R., \& Jamieson, S. (1986). Beta 1- and beta 2adrenergic-receptor subpopulations in nonfailing and failing human ventricular myocardium: Coupling of both receptor subtypes to muscle contraction and selective beta 1-receptor down-regulation in heart failure. Circulation Research, 59(3), 297-309. https://doi.org/10. 1161/01.RES.59.3.297

Communal, C., Singh, K., Pimentel, D. R., \& Colucci, W. S. (1998). Norepinephrine stimulates apoptosis in adult rat ventricular myocytes by activation of the $\beta$-adrenergic pathway. Circulation, 98(13), 1329-1334. https://doi.org/10.1161/01.CIR.98.13.1329

Communal, C., Singh, K., Sawyer, D. B., \& Colucci, W. S. (1999). Opposing effects of $\beta 1$ - and $\beta 2$-adrenergic receptors on cardiac myocyte apoptosis. Circulation, 100(22), 2210-2212. https://doi.org/10.1161/ 01.CIR.100.22.2210

Demion, M., Thireau, J., Gueffier, M., Finan, A., Khoueiry, Z., Cassan, C., \& Richard, S. (2014). Trpm4 gene invalidation leads to cardiac hypertrophy and electrophysiological alterations. PLoS One, 9(12), e115256. https://doi.org/10.1371/journal.pone.0115256

Dong, F., Harvey, J., Finan, A., Weber, K., Agarwal, U., \& Penn, M. S. (2012). Myocardial CXCR4 expression is required for mesenchymal stem cell mediated repair following acute myocardial infarction. Circulation, 126(3), 314-324. https://doi.org/10.1161/CIRCULATIONAHA.111. 082453 
Ellison, G. M., Torella, D., Karakikes, I., Purushothaman, S., Curcio, A., Gasparri, C., \& Nadal-Ginard, B. (2007). Acute $\beta$-adrenergic overload produces myocyte damage through calcium leakage from the ryanodine receptor 2 but spares cardiac stem cells. The Journal of Biological Chemistry, 282(15), 11397-11409. https://doi.org/10.1074/ jbc.M607391200

Ellison, G. M., Vicinanza, C., Smith, A. J., Aquila, I., Leone, A., Waring, C. D., \& Nadal-Ginard, B. (2013). Adult c-kitpos cardiac stem cells are necessary and sufficient for functional cardiac regeneration and repair. Cell, 154(4), 827-842. https://doi.org/10.1016/j.cell.2013.07.039

Fajardo, G., Zhao, M., Urashima, T., Farahani, S., Hu, D. -Q., Reddy, S., \& Bernstein, D. (2013). Deletion of the $\beta 2$-adrenergic receptor prevents the development of cardiomyopathy in mice. Journal of Molecular and Cellular Cardiology, 63, 155-164. https://doi.org/10. 1016/j.yjmcc.2013.07.016

Fanton, Y., Houbrechts, C., Willems, L., Daniëls, A., Linsen, L., Ratajczak, J., \& Hensen, K. (2016). Cardiac atrial appendage stem cells promote angiogenesis in vitro and in vivo. Journal of Molecular and Cellular Cardiology, 97, 235-244. https://doi.org/10.1016/j.yjmcc.2016.06.005

Fazel, S. (2006). Cardioprotective c-kit+ cells are from the bone marrow and regulate the myocardial balance of angiogenic cytokines. Journal of Clinical Investigation, 116(7), 1865-1877. https://doi.org/10.1172/ $\mathrm{JCl} 27019$

Finan, A., Kiedrowski, M., Turturice, B. A., Sopko, N. A., \& Penn, M. S. (2012). Cardiac pressure overload initiates a systemic stem cell response. Cytotherapy, 14(8), 983-993. https://doi.org/10.3109/ 14653249.2012.684380

Finan, A., \& Richard, S. (2015). Stimulating endogenous cardiac repair. Frontiers in Cell and Developmental Biology, 3, 57. https://doi.org/10. 3389/fcell.2015.00057

Finan, A., Sopko, N., Dong, F., Turturice, B., Kiedrowski, M., \& Penn, M. S. (2013). Bone marrow SSEA1+ cells support the myocardium in cardiac pressure overload. PLoS One, 8(7), e68528. https://doi.org/10.1371/ journal.pone.0068528

Fransioli, J., Bailey, B., Gude, N. A., Cottage, C. T., Muraski, J. A., Emmanuel, G., \& Sussman, M. A. (2008). Evolution of the c-kit-positive cell response to pathological challenge in the myocardium. Stem Cells (Dayton, Ohio), 26(5), 1315-1324. https://doi.org/10.1634/stemcells. 2007-0751

Galasso, G., Rosa, R. D., Ciccarelli, M., Sorriento, D., Giudice, C. D., Strisciuglio, T., \& laccarino, G. (2013). $\beta 2$-adrenergic receptor stimulation improves endothelial progenitor cell-mediated ischemic neoangiogenesis. Circulation Research, 112(7), 1026-1034. https://doi. org/10.1161/CIRCRESAHA.111.300152

Grisanti, L. A., Gumpert, A. M., Traynham, C. J., Gorsky, J. E., Repas, A. A., Gao, E., \& Tilley, D. G. (2016). Leukocyte-expressed $\beta 2-$ adrenergic receptors are essential for survival after acute myocardial injury. Circulation, 134(2), 153-167. https://doi.org/10. 1161/CIRCULATIONAHA.116.022304

Grisanti, L. A., Traynham, C. J., Repas, A. A., Gao, E., Koch, W. J., \& Tilley, D. G. (2016). $\beta 2$-adrenergic receptor-dependent chemokine receptor 2 expression regulates leukocyte recruitment to the heart following acute injury. Proceedings of the National Academy of Sciences, 113(52), 15126-15131. https://doi.org/10.1073/pnas. 1611023114

Hinkel, R. (2016). Pim1 Overexpressing $\mathrm{ckit}^{+}$cardiac stem cells in cardiac regeneration: Preconditioning as next-generation stem cell therapy? Journal of the American College of Cardiology, 68(22), 2465-2466. https://doi.org/10.1016/j.jacc.2016.09.924

Hirst, S. J., Martin, J. G., Bonacci, J. V., Chan, V., Fixman, E. D., Hamid, Q. A., \& Stewart, A. G. (2004). Proliferative aspects of airway smooth muscle. The Journal of Allergy and Clinical Immunology, 114(2 Suppl), S2-S17. https://doi.org/10.1016/j.jaci.2004.04.039

Janssens, S., Dubois, C., Bogaert, J., Theunissen, K., Deroose, C., Desmet, W., \& Van de Werf, F. (2006). Autogolous bone marrow-derived stem- cell transfer in patients with ST segment elevation myocardial infarction: Double-blind, randomised controlled trial. Lancet, 367(9505), 113-121. https://doi.org/10.1016/S0140-6736(05)67861-0

Jopling, C., Sleep, E., Raya, M., Martí, M., Raya, A., \& Belmonte, J. C. I. (2010). Zebrafish heart regeneration occurs by cardiomyocyte dedifferentiation and proliferation. Nature, 464(7288), 606-609. https://doi.org/10.1038/nature08899

Katayama, Y., Battista, M., Kao, W. -M., Hidalgo, A., Peired, A. J., Thomas, S. A., \& Frenette, P. S. (2006). Signals from the sympathetic nervous system regulate hematopoietic stem cell egress from bone marrow. Cell, 124(2), 407-421. https://doi.org/ 10.1016/j.cell.2005.10.041

Keller, K. M., \& Howlett, S. E. (2016). Sex differences in the biology and pathology of the aging heart. Canadian Journal of Cardiology, 32(9), 1065-1073. https://doi.org/10.1016/j.cjca.2016.03.017

Khan, M., Mohsin, S., Avitabile, D., Siddiqi, S., Nguyen, J., Wallach, K., \& Sussman, M. A. (2013). $\beta$-adrenergic regulation of cardiac progenitor cell death versus survival and proliferation. Circulation Research, 112(3), 476-486. https://doi.org/10.1161/CIRCRESAHA.112. 280735

Lameris, T. W., Zeeuw, S., de, Alberts, G., Boomsma, F., Duncker, D. J., Verdouw, P. D., \& Meiracker, A. H. van den (2000). Time course and mechanism of myocardial catecholamine release during transient ischemia in vivo. Circulation, 101(22), 2645-2650. https://doi.org/10. 1161/01.CIR.101.22.2645

Lang, D., Holzem, K., Kang, C., Xiao, M., Hwang, H. J., Ewald, G. A., \& Efimov, I. R. (2015). Arrhythmogenic remodeling of $\beta 2$ versus $\beta 1$ adrenergic signaling in the human failing heart. Circulation. Arrhythmia and Electrophysiology, 8(2), 409-419. https://doi.org/10.1161/CIRCEP. 114.002065

Le, T. Y. L., \& Chong, J. J. H. (2016). Cardiac progenitor cells for heart repair. Cell Death Discovery, 2, 16052. https://doi.org/10.1038/ cddiscovery.2016.52

Lohse, M. J., Engelhardt, S., \& Eschenhagen, T. (2003). What is the role of $\beta$-adrenergic signaling in heart failure? Circulation Research, 93(10), 896-906. https://doi.org/10.1161/01.RES.0000102042. 83024.CA

Lucas, A., Mialet-Perez, J., Daviaud, D., Parini, A., Marber, M. S., \& Sicard, P. (2015). Gadd $45 \gamma$ regulates cardiomyocyte death and postmyocardial infarction left ventricular remodelling. Cardiovascular Research, 108(2), 254-267. https://doi.org/10.1093/cvr/cvv219

Lucas, D., Bruns, I., Battista, M., Mendez-Ferrer, S., Magnon, C., Kunisaki, Y., \& Frenette, P. S. (2012). Norepinephrine reuptake inhibition promotes mobilization in mice: Potential impact to rescue low stem cell yields. Blood, 119(17), 3962-3965. https://doi.org/10.1182/blood2011-07-367102

Lukovic, D., Zlabinger, K., Gugerell, A., Spannbauer, A., Pavo, N., Mandic, L., ... Gyöngyösi, M. (2016). Inhibition of CD34+ cell migration by matrix metalloproteinase-2 during acute myocardial ischemia, counteracted by ischemic preconditioning. F1000Research, 5, 2739. https:// doi.org/10.12688/f1000research.9957.3

Makkar, R. R., Smith, R. R., Cheng, K., Malliaras, K., Thomson, L. E. J., Berman, D., \& Marbán, E. (2012). Intracoronary cardiospherederived cells for heart regeneration after myocardial infarction (CADUCEUS): A prospective, randomised phase 1 trial. Lancet (London, England), 379(9819), 895-904. https://doi.org/10.1016/ S0140-6736(12)60195-0

Mayorga, M., Finan, A., \& Penn, M. (2009). Pre-transplantation specification of stem cells to cardiac lineage for regeneration of cardiac tissue. Stem Cell Reviews, 5(1), 51-60. https://doi.org/10.1007/s12015-0099050-8

Moelker, A. D., Baks, T., van den Bos, E. J., van Geuns, R. J., de Feyter, P. J., Duncker, D. J., \& van der Giessen, W. J. (2006). Reduction in infarct size, but no functional improvement after bone marrow cell administration in a porcine model of reperfused myocardial infarction. 
European Heart Journal, 27(24), 3057-3064. https://doi.org/10.1093/ eurheartj/ehl401

Myagmar, B. -E., Flynn, J. M., Cowley, P. M., Swigart, P., Montgomery, M., Thai, K., \& Simpson, P. C. (2017). Adrenergic receptors in individual ventricular myocytes: The beta- 1 and alpha-1B are in all cells, the alpha- $1 \mathrm{~A}$ is in a subpopulation, and the beta- 2 and beta- 3 are mostly absent. Circulation Research, CIRCRESAHA, 117, 310520. https://doi. org/10.1161/CIRCRESAHA.117.310520

Najafi, A., Sequeira, V., Kuster, D. W. D., \& van der Velden, J. (2016). $\beta$ adrenergic receptor signalling and its functional consequences in the diseased heart. European Journal of Clinical Investigation, 46(4), 362-374. https://doi.org/10.1111/eci.12598

Pagano, F., Angelini, F., Siciliano, C., Tasciotti, J., Mangino, G., De Falco, E., \& Chimenti, I. (2018). Beta2-adrenergic signaling affects the phenotype of human cardiac progenitor cells through EMT modulation. Pharmacological Research, 127, 41-48. https://doi.org/10.1016/j. phrs.2017.01.016

Prichard, B. N., Owens, C. W., Smith, C. C., \& Walden, R. J. (1991). Heart and catecholamines. Acta Cardiologica, 46(3), 309-322.

Quaini, F., Urbanek, K., Beltrami, A. P., Finato, N., Beltrami, C. A., Nadal-Ginard, B., \& Anversa, P. (2002). Chimerism of the transplanted heart. New England Journal of Medicine, 346(1), 5-15. https://doi.org/ 10.1056/NEJMoa012081

Roncalli, J., Mouquet, F., Piot, C., Trochu, J. -N., Le Corvoisier, P., Neuder, Y., \& Lemarchand, P. F. (2011). Intracoronary autologous mononucleated bone marrow cell infusion for acute myocardial infarction: Results of the randomized multicenter BONAMI trial. European Heart Journal, 32(14), 1748-1757. https://doi.org/10.1093/eurheartj/ehq455

Rota, M., Goichberg, P., Anversa, P., \& Leri, A. (2015). Aging effects on cardiac progenitor cell physiology. Comprehensive Physiology, 5(4), 1775-1814. https://doi.org/10.1002/cphy.c140082

Rybin, V. O., Xu, X., Lisanti, M. P., \& Steinberg, S. F. (2000). Differential targeting of $\beta$-adrenergic receptor subtypes and adenylyl cyclase to cardiomyocyte caveolae a mechanism to functionally regulate the cAMP signaling pathway. Journal of Biological Chemistry, 275(52), 41447-41457. https://doi.org/10.1074/jbc.M006951200

Sandstedt, J., Jonsson, M., Lindahl, A., Jeppsson, A., \& Asp, J. (2010). C-kit+ CD45-cells found in the adult human heart represent a population of endothelial progenitor cells. Basic Research in Cardiology, 105(4), 545-556. https://doi.org/10.1007/s00395-010-0088-1

Schömig, A. (1990). Catecholamines in myocardial ischemia. Systemic and cardiac release. Circulation, 82(3 Suppl), II13-II22.

Shi, Q., Li, M., Mika, D., Fu, Q., Kim, S., Phan, J., \& Xiang, Y. K. (2017). Heterologous desensitization of cardiac $\beta$-adrenergic signal via hormone-induced $\beta A R / a r r e s t i n / P D E 4$ complexes. Cardiovascular Research, 113(6), 656-670. https://doi.org/10.1093/cvr/cvx036

Straface, E., Gambardella, L., Pagano, F., Agnelini, F., Ascione, B., Vona, R., \& Chimenti, I. (2017). Sex differences of human cardiac progenitor cells in the biological response to TNF- $\alpha$ treatment. Stem Cells International, 2017, 4890563-4890569. https://doi.org/10.1155/ 2017/4790563

Takagi, G., Asai, K., Vatner, S. F., Kudej, R. K., Rossi, F., Peppas, A., \& Vatner, D. E. (2003). Gender differences on the effects of agining on cardiac and peripheral adrenergic stimulation in old consious monkeys. American Journal of Physiology - Heart and Circulatory Physiology, 285(2), H527-H534. https://doi.org/10.1152/ajpheart. 01034.2002

Urbanek, K., Quaini, F., Tasca, G., Torella, D., Castaldo, C., Nadal-Ginard, B., \& Anversa, P. (2003). Intense myocyte formation from cardiac stem cells in human cardiac hypertrophy. Proceedings of the National Academy of Sciences of the United States of America, 100(18), 1044010445. https://doi.org/10.1073/pnas.1832855100

Vizgirdi, V. M., Wahler, G. M., Sondgeroth, K. L., Ziolo, M. T., \& Schwertz, D. W. (2002). Mechanims of sex differences in rat cardiac myocyte response to beta adrenergic stimulation. American Journal of Physiology - Heart and Circulatory Physiology, 282(1), H256-H263. https://doi.org/10.1152/ ajpheart.2002.282.1. $\mathrm{H} 256$

Wallner, M., Duran, J. M., Mohsin, S., Troupes, C. D., Vanhoutte, D., Borghetti, G., \& Houser, S. R. (2016). Acute catecholamine exposure causes reversible myocyte injury without cardiac regeneration novelty and significance. Circulation Research, 119(7), 865-879. https://doi.org/10.1161/CIRCRESAHA.116.308687

White, M., Roden, R., Minobe, W., Khan, M. F., Larrabee, P., Wollmering, M., \& Feldman, A. M. (1994). Age-related changes in beta-adrenergic neuroeffector systems in the human heart. Circulation, $90(3)$, $1225-1238$.

Woo, A. Y. H., \& Xiao, R. (2012). $\beta$-Adrenergic receptor subtype signaling in heart: From bench to bedside. Acta Pharmacologica Sinica, 33(3), 335-341. https://doi.org/10.1038/aps.2011.201

Xiao, R.-P., Zhang, S.-J., Chakir, K., Avdonin, P., Zhu, W., Bond, R. A., \& Cheng, H. (2003). Enhanced Gi signaling selectively negates $\beta 2$-adrenergic receptor (AR)- but not $\beta 1$-AR-mediated positive inotropic effect in myocytes from failing rat hearts. Circulation, 108(13), 1633-1639. https://doi.org/10.1161/01.CIR.0000087595. 17277.73

Zhang, Q., Xiang, J., Wang, X., Liu, H., Hu, B., Feng, M., \& Fu, Q. (2010). ß2adrenoceptor agonist clenbuterol reduces infarct size and myocardial apoptosis after myocardial ischaemia/reperfusion in anaesthetized rats. British Journal of Pharmacology, 160(6), 1561-1572. https://doi. org/10.1111/j.1476-5381.2010.00813.x 